\title{
Neonatal Vallecular Cyst: Unusual Presentation with Near Catastrophic Respiratory Distress and Successful Treatment Using Endoscopy-assisted Plasma Ablation: A Case Report
}

\author{
Vimmi Gautam ${ }^{1}$, Anant Basotia ${ }^{2}$, Ramandeep Virk ${ }^{3}$
}

\begin{abstract}
Congenital vallecular cyst is a rare benign laryngeal lesion which may cause stridor and life-threatening upper airway obstruction in infants. We present a case of a 4-week-old child who had respiratory distress since birth and was intubated on day 3 of life. On failure of repeated extubation trial, the child was evaluated by the otolaryngology team and a direct laryngoscopy was done which showed a cyst in the vallecula obscuring $90 \%$ of the oropharyngeal lumen. Computed tomography scan was ordered which showed a hypodense round lesion in the vallecula confirming the diagnosis. The child underwent endoscopic-assisted plasma ablation of the cyst and was successfully extubated the next day. Keywords: Endoscope, Plasma ablation, Vallecular cyst.

Journal of Postgraduate Medicine Education and Research (2020): 10.5005/jp-journals-10028-1349
\end{abstract}

\section{INTRODUCTION}

Congenital laryngeal cysts are a rare entity and are potentially dangerous because of inspiratory stridor in newborns and have an incidence of $5 \%$ of all benign laryngeal lesions. ${ }^{1,2}$ The annual incidence of vallecular cysts shows a variation among many studies: from 5.3 cases per 100,000 live births to 1.87 and 3.49 cases per 100,000 live births. ${ }^{3,4}$ Stridor with or without respiratory distress is the most common presentation secondary to narrowing of the airway. Even though there have been many cases reported in the literature, we strongly believe that medical officers in district hospitals or even smaller clinics, including pediatricians and general practitioners, need to be made aware that this condition exists so that it can be quickly identified and affected children can be managed promptly and appropriately. Here we present the case of a 4-week-old child who had respiratory distress since birth and upon evaluation was diagnosed to have a cyst in the vallecula and was effectively managed by endoscopic-assisted plasma ablation.

\section{Case Description}

The child was referred to our center on day 24 of birth, delivered preterm via lower segment caesarian section in view of fetal distress. There was a history of delayed cry at birth. There was an episode of focal seizures and suspected hypoxic ischemic encephalopathy on day 3 following which the child was intubated and put on ventilatory support. An extubation trial on day 20 failed following which the child was reintubated and referred to our center. Chest X-ray was done which revealed a collapse of the upper lobe of the right lung. The child was evaluated under pediatric pulmonology and was being treated on grounds of suspected pneumonia. Extubation trial on day 28 failed again following which otolaryngology opinion was sought. Direct laryngoscopy was done bedside which revealed a huge cystic lesion in the vallecula. Computed tomography scan was ordered which showed a rounded hypodense lesion in the oropharynx. Thyroid lobes were present in their normal position. Thyroid function tests were normal. There have been a variety of
${ }^{1-4}$ Department of ENT, Postgraduate Institute of Medical Education and Research, Chandigarh, India

Corresponding Author: Ramandeep Virk, Department of ENT, Postgraduate Institute of Medical Education and Research, Chandigarh, India, Phone: +91 9814222220, e-mail: virkdoc@hotmail.com

How to cite this article: Gautam V, Basotia A, Virk R. Neonatal Vallecular Cyst: Unusual Presentation with Near Catastrophic Respiratory Distress and Successful Treatment Using Endoscopy-assisted Plasma Ablation: A Case Report. J Postgrad Med Edu Res 2020;54(1):15-16.

Source of support: Nil

Conflict of interest: None

treatment options proposed. Aspiration was not recommended, as these cysts would likely recur. Laser and cold instrumentation dissection have been described for removal. The child was planned for endoscope-assisted plasma ablation of the cyst which results in bloodless dissection and no risk of airway fire and minimal mucosal edema.

We use the four-hand technique. A $0^{\circ} 4 \mathrm{~mm}$ Hopkins Rod nasal endoscope, Millers laryngoscope blade, and Plasma Ablation (Smith and Nephew, USA) were used for this procedure. ${ }^{5}$ The assistant inserts the laryngoscope blade into the oral cavity and a $4 \mathrm{~mm}$ nasal endoscope is inserted through the miller blade visualizing the vallecular cyst (Fig. 1). Following this the surgeon introduces the Procise max Coblation wand into the oral cavity (Fig. 2) and if needed an extra suction can also be introduced. Prominent blood vessels on the cyst wall are first coagulated in order to minimize bleeding into the surgical field. The cyst is then ablated away and excision is carried onto the base making sure to remove the lining completely (Fig. 3). Postoperatively, there is minimal edema due to low temperatures involved in the technique. The surgical time is also less because the laryngoscope does not have to be fixed with a chest support. The endoscope also gives us a panoramic wide angle view.

() The Author(s). 2020 Open Access This article is distributed under the terms of the Creative Commons Attribution 4.0 International License (https://creativecommons. org/licenses/by-nc/4.0/), which permits unrestricted use, distribution, and non-commercial reproduction in any medium, provided you give appropriate credit to the original author(s) and the source, provide a link to the Creative Commons license, and indicate if changes were made. The Creative Commons Public Domain Dedication waiver (http://creativecommons.org/publicdomain/zero/1.0/) applies to the data made available in this article, unless otherwise stated. 


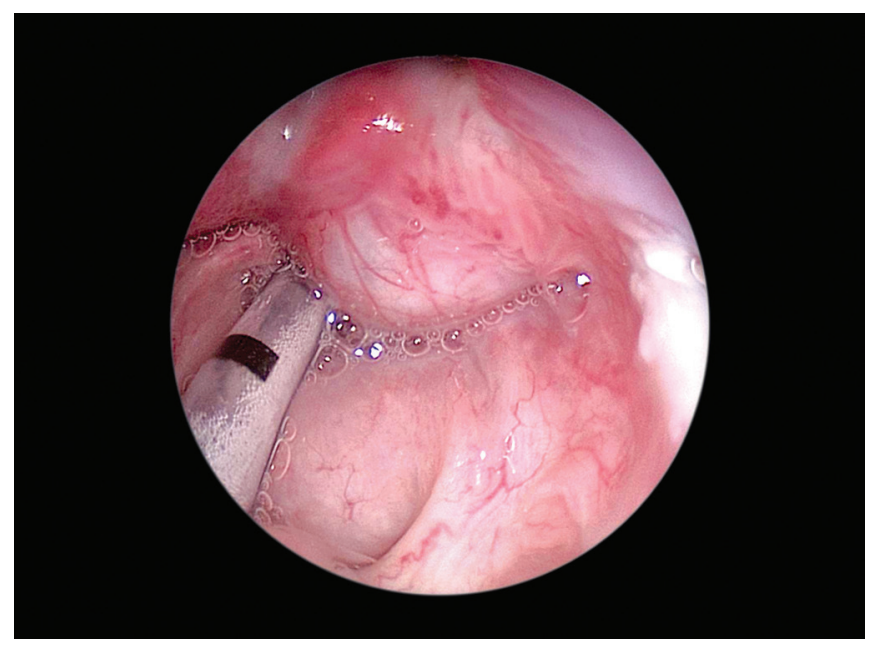

Fig. 1: Visualization of the vallecular cyst

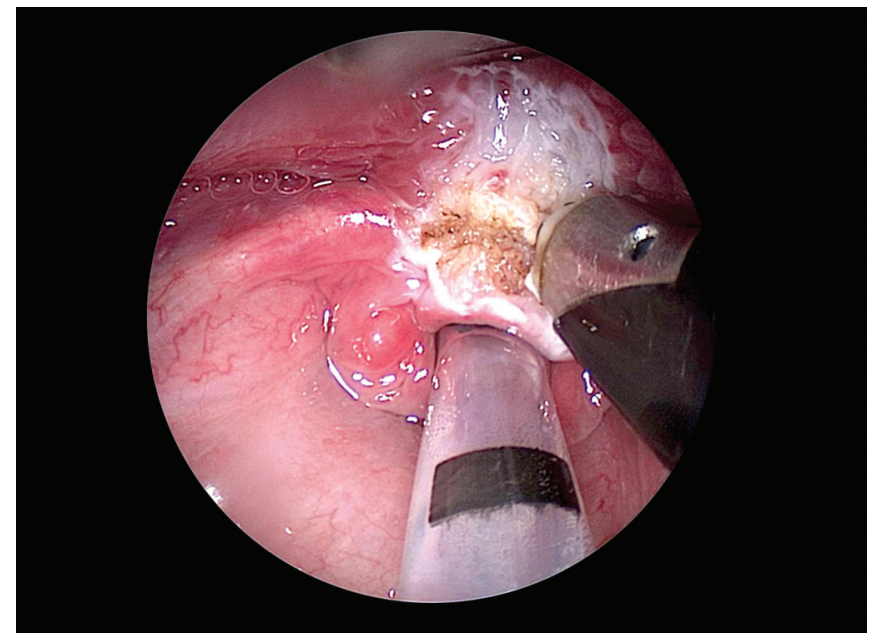

Fig. 3: Final picture with cyst removed completely

\section{Discussion}

The vallecular cyst is a unilocular cystic mass of variable size that arises from the lingual surface of the epiglottis and usually contains clear, noninfected fluid. ${ }^{6,7}$ It is a ductal type of laryngeal cyst, which arises from fluid accumulation secondary to obstructed submucosal glands. The other type is a saccular cyst, which is submucosal cyst caused by mucous accumulation within the laryngeal saccule. ${ }^{8}$ When a laryngeal lesion is suspected, visualization is best done by direct laryngoscopy or fiberoptic laryngoscopy as the presence of the lesion can be confirmed and the degree of airway compromise can be assessed. Imaging modalities such as CT or MRI are useful, as they can provide information concerning the nature and extent of the lesion, particularly in the preoperative setting.

Awareness and a high level of suspicion are required for a quick diagnosis of a laryngeal lesion. Vallecular cysts are usually missed and remain undiagnosed. This leads to prolonged intubation and its sequalae as well as pulmonary and neurological complications as seen in our case. Direct laryngoscopy/fiberoptic laryngoscopy is the gold standard for diagnosis. Surgical excision of the cyst is the treatment of choice and, when performed in a timely manner has

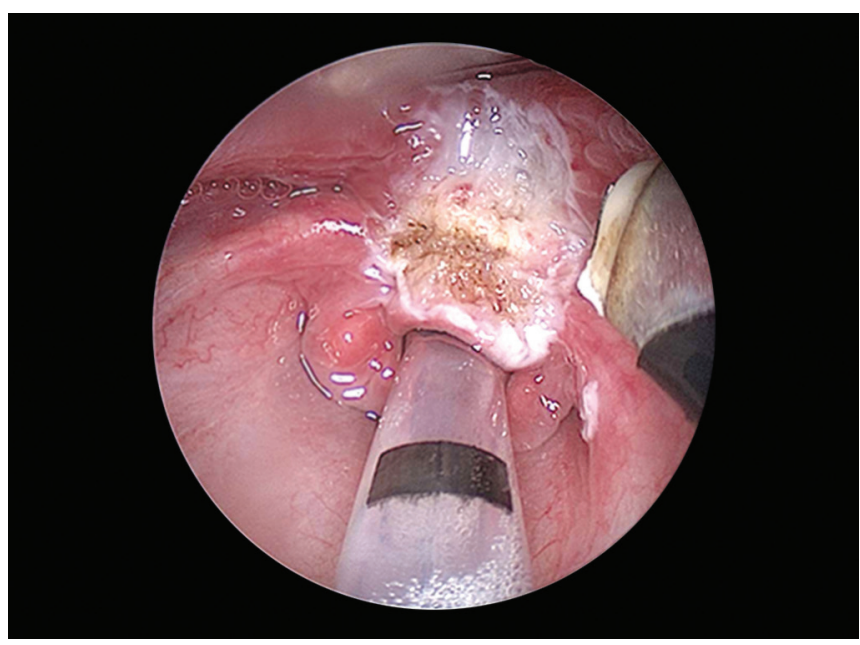

Fig. 2: Plasma ablation wand ablating the cyst

a good prognosis. This case was managed by plasma ablation. It creates a controlled plasma field to precisely remove tissue at a low temperature, resulting in minimal thermal damage to surrounding soft tissues and structures. Temperatures range between $40^{\circ} \mathrm{C}$ and $70^{\circ} \mathrm{C}$ with thermal penetration of less than $1100 \mu \mathrm{m} .{ }^{9}$

\section{Conclusion}

Endoscopic-assisted plasma ablation of congenital vallecular cyst is a safe procedure. It is quick, precise, and bloodless. There is no edema or charring postoperatively and there is no risk of airway fire.

\section{References}

1. Sands NB, Anand SM, Manoukian JJ. Series of congenital vallecular cysts: a rare yet potentially fatal cause of upper airway obstruction and failure to thrive in the newborn. J Otolaryngol Head Neck Surg 2009;38(1):6-10.

2. Cheng KS, Ng JM, Li HY, et al. Vallecular cyst and laryngomalacia in infants: report of six cases and airway management. Anesth Analg 2002;95(5):1248-1250. DOI: 10.1097/00000539-200211000-00026.

3. Pak MW, Woo JK, van Hasselt CA. Congenital laryngeal cysts: current approach to management. J Laryngol Otol 1996;110(9):854-856. DOI: 10.1017/S0022215100135157.

4. Prowse S, Knight L. Congenital cysts of the infant larynx. Int J Pediatr Otorhinolaryngol 2012;76(5):708-711. DOI: 10.1016/ j.jporl.2012.02.025.

5. Virk RS, Nayak G, Divya J. Miller laryngoscope blade: an aid to pediatric laryngeal surgery. Indian J Otolaryngol Head Neck Surg 2019;71(1):19-21. DOI: 10.1007/s12070-018-1501-6.

6. Yang MA, Kang MJ, Hong J, et al. A case of congenital vallecular cyst associated with gastroesophageal reflux presenting with stridor, feeding cyanosis, and failure to thrive. Korean J Pediatr 2008;51(7):775-779. DOI: 10.3345/kjp.2008.51.7.775.

7. Gutierrez JP, Berkowitz RG, Robertson CF. Vallecular cysts in newborns and young infants. Pediatr Pulmonol 1999;27(4):282-285. DOI: 10.1002/(SICI)1099-0496(199904)27:4<282::AID-PPUL10>3.0.CO;2-G.

8. Brown DJ. Pediatric stridor. In: Mitchell RB, Pereira KD. Fundamentals of pediatric otolaryngology for the clinician. New York: Humana Press; 2009. pp. 137-147.

9. Virk R, Mathew J, Behera S, et al. Endoscopic assisted coblation of congenital vallecular cyst - a novel technique. Indian J Pediatr 2016;83(8):888-889. DOI: 10.1007/s12098-016-2095-1. 